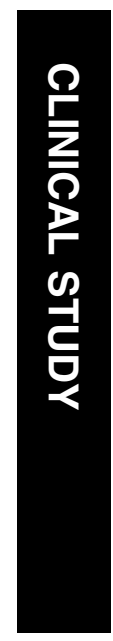

\title{
Macular pigment optical density in wet age-related macular degeneration among Indians
}

\begin{abstract}
Purpose To estimate the value of macular pigment optical density (MPOD) in adult south Indian population with wet age-related macular degeneration (AMD).

Methods A total of 33 patients with wet AMD and 29 age-matched controls $>50$ years of age underwent MPOD measurement with the macular densitometer. The patients were also tested for their dietary intake of carotenoids, smoking history, and lifetime UV exposure.

Results The mean MPOD values in the Indian population with wet AMD was 0.23 (95\% CI: 0.18-0.29) vs control was 0.43 (95\% CI: $0.37-0.49), P<0.0001$, at $0.5^{\circ}$ eccentricity.

Ex-smokers had a lower MPOD than nonsmokers (0.16 (0.09-0.23) vs 0.28 (0.22-0.34), $P=0.026)$ and the lowest level of carotenoids intake had $48 \%$ lower MPOD than the highest level (0.14 (0.08-0.21) vs 0.33 (0.24-0.43), $P=0.012)$. There was no significant age-related decline or gender variation in MPOD.

Conclusion This study establishes the MPOD in adult Indian population with wet AMD, with a lack of macular pigment in association with wet AMD.

Eye (2012) 26, 1052-1057; doi:10.1038/eye.2012.86;

published online 25 May 2012
\end{abstract}

'Shri Bhagwan Mahavir Vitreoretinal Services, Chennai, India

2Elite School of Optometry, Chennai, India

${ }^{3}$ Department of Preventive Ophthalmology, Chennai, India

Correspondence: R Raman, Shri Bhagwan Mahavir Vitreoretinal Services, Sankara Nethralaya, 18, College Road, Chennai 600006 , Tamil Nadu, India Tel: +9144 2827 1616; Fax: + 914428254180 . E-mail: rajivpgraman@ gmail.com

Received: 7 October 2011 Accepted in revised form: 29 March 2012

Published online: 25 May 2012
Keywords: macular pigment; age-related macular degeneration; carotenoids; lutein; zeaxanthin; ultraviolet

\section{Introduction}

Age-related macular degeneration (AMD) is one of the causes of irreversible blindness in people $>50$ years of age. ${ }^{1,2}$ It has been estimated that
R Raman1, S Biswas², K Vaitheeswaran ${ }^{3}$ and T Sharma'
8 million people will be affected with AMD worldwide by the year $2020 .^{3}$ In India, the population $\geq 60$ years is expected to increase by 2.5-fold in 30 years (projected from 71 million in 2001 to 177.5 million in 2031). ${ }^{4}$ INDEYE study have reported the prevalence of wet AMD in India to be $1.2 \% .^{1}$ This prevalence is low as compared with the western populations. 5,6

Previous studies have shown that high intake of dietary carotenoids and high plasma levels of carotenoids are related to the reduced risk of AMD in many population. ${ }^{7,8}$ The prevailing vegetarian dietary pattern among Indians may influence the macular carotenoids and thereby the prevalence of AMD.

However, there is lack of data on macular carotenoids and AMD in the Indian population. The aim of the study is to elucidate the mean macular pigment optical density (MPOD) in subjects with wet AMD in south Indian population.

\section{Materials and methods}

Between the years 2003-2006, a genome-wide association study (GWAS) was done in southern India (unpublished data) for the estimation of genetic risk factors for wet $\mathrm{AMD}^{9}$ in Indian ethnicity. It was a case-control study consisting of 230 individuals of south Indian ethnicity aged $\geq 50$ years, out of which 120 were unrelated cases and 110 was their age-matched controls. These subjects were recruited from the Vitreo-retinal out-patient clinic at the eye institute. The ancestral origin/ethnicity of the subjects was established through self-reporting or an open questionnaire. An informed consent was obtained from the subjects. Out of the subjects recruited in the GWAS, 33 cases and 29 controls were recruited for the present study. 
The study was done after clearance from the institutional review board was obtained, and followed the principles of the Declaration of Helsinki.

Inclusion criteria of cases for the present study included age $\geq 50$ years, presence of wet $\mathrm{AMD},{ }^{9}$ and a best-corrected visual acuity (BCVA) of better than or equal to 6/60 (log MAR 1.0). In patients with unilateral wet $A M D$, the diseased eye was included in the study. In patients having bilateral advanced AMD, the eye with the better BCVA (but still $\leq 6 / 60$ ) was included. If both the eyes of the patient had wet AMD and similar BCVA, then one eye was tested randomly. The patients having any ocular pathology other than wet AMD, and those who underwent vitreo-retinal surgery, retinal laser photocoagulation were excluded from the study. Healthy eyes without any ocular pathology were included as age-matched controls. One eye of each control was tested randomly to minimize any potential order effect.

A detailed questionnaire was administered to ascertain the demographic, lifestyle, and medical history of the patients. Smoking history was elicited and smoking pack years were then calculated by using the formula, ((Number of cigarettes smoked per day $\times$ Number of years smoked)/20). ${ }^{10}$ Smokers were defined as those who have smoked in the past or currently smoking. Non-smokers are those who have never smoked in their lifetime. A validated semiquantitative food-frequency questionnaire (FFQ) was used to estimate the dietary consumption of lutein and zeaxanthin, which included questions about the usual intakes of the Indian foods rich in lutein and zeaxanthin. ${ }^{11}$

The lifetime ocular UV exposure data collection was done as per the Melbourne visual impairment project model. ${ }^{12}$ In short, it contains collection of data on details on migration, use of protective devices based on questionnaire, and details on UV radiation exposure at the location based on the geographical location.

Anthropometric measurements including weight and height were obtained using standardized techniques. Height was measured with a tape to the nearest centimetre. ${ }^{13}$ Subjects were requested to stand upright without shoes with their back against the wall, heels together, and eyes directed forward. Weight was measured with a traditional spring balance that was kept on a firm horizontal surface. Subjects were asked to wear light clothing and weight was recorded to the nearest $0.5 \mathrm{~kg}$. Body mass index (BMI) was calculated by using the formula: weight $(\mathrm{kg}) /$ height $(\mathrm{m})^{2} \cdot{ }^{13,14}$

A comprehensive eye examination was done, including assessment of the best-corrected visual acuity (modified ETDRS chart, Light House Low Vision Products, New York, NY, USA), Slit-Lamp examination (Zeiss SL 130, Carl Zeiss, Jena, Germany), and intraocular pressure measurement were done using Goldmann applanation tonometer (Zeiss AT 030, Carl Zeiss), followed by the assessment of macular MPOD with Macular Densitometer (Macular Metrics Corp., Rehoboth, MA, USA). All the patients were naive in psychophysical tasks. Retinal photographs were obtained after pupillary dilatation, $30^{\circ}$ 3-field stereoscopic digital photography with a Carl Zeiss fundus camera (Visucamlite, Jena, Germany). Dilated retinal evaluation was done with indirect ophthalmoscopy to exclude other retinal pathologies.

MPOD was calculated using the Macular Densitometer. ${ }^{15,16}$ One eye of the patient was tested randomly to minimize any potential order effect or the eye meeting the criteria. MPOD was measured at $0.50^{\circ}$ and $7^{\circ}$ foveal eccentricities. Patients requiring distance refractive error correction was provided the correction in trial frames or allowed to wear their spectacles.

The dimension of the target was a solid disk of $0.5^{\circ}$ arc radius (to derive a measure at $0.50^{\circ}$ foveal eccentricity). A small black dot was present at the centre of the solid disks as a fixation aid. The wavelength composition of the test stimulus alternated between $460 \mathrm{~nm}$ (peak macular pigment absorbance) and $540 \mathrm{~nm}, 1.7 \log \mathrm{Td}$ reference field (minimal macular pigment absorbance) in a yoked manner. The parafoveal measurement was measured by asking the subjects to fixate on a red light located precisely at $7^{\circ}$ from central fixation.

The patients were trained till they were able to confidently recognize the null zone (ie, zone of no/ minimal flicker). The starting flicker frequency was set at $10-11 \mathrm{~Hz}$. For participants having difficulty adjusting the knob on their own, we performed the task on their behalf, instructing them to notify us immediately upon cessation of the flicker sensation.

Readings were deemed reliable and included in the study only if the SD of the readings (radiance measurements of the $460-\mathrm{nm}$ light that provides null zone) did not exceed $0.20 \log$ unit. $^{16}$

\section{Statistical analysis}

The normality distribution was checked for all quantitative variables. Statistical analyses were performed using SPSS for Windows version 14.0 software (SPSS Inc., Chicago, IL, USA). The student's $t$-test was used to analyse the continuous variable MPOD. Groups with more than two categorical variables were analysed using the one-way analysis of variance test. The adjusted mean MPOD in AMD was analysed using analysis of covariance. A $P$-value $\leq 0.05$ was considered to be significant. The measurement of MPOD by two observers was plotted against the other and their difference against the average in a Bland-Altman plot. The dietary levels of lutein and zeaxanthin between controls and wet AMD eyes were checked. 


\section{Results}

The mean age of AMD cases $(n=33)$ and controls $(n=29)$ were $71.85 \pm 7.6$ years and $68.69 \pm 6.8$ years, respectively $(P=0.09)$.

Figure 1 shows the age- and gender-adjusted mean MPOD in patients with wet AMD and without AMD. MPOD among patients with AMD was 0.23 (95\% CI: $0.18-0.29)$ and that of healthy controls was 0.43 (95\% CI: 0.37-0.49), $P<0.0001$.

Table 1 shows the mean MPOD in various subgroups. Unadjusted MPOD was found to be significantly different among smokers and non-smokers and quartiles of dietary intake of carotenoids. Smokers had a lower MPOD than the non-smokers $(0.18 \pm 0.12$ vs $0.27 \pm 0.12$, $P=0.041$ ). MPOD was found to be lower among the first quartile of dietary carotenoid intake than the fourth quartile $(0.15 \pm 0.07$ vs $0.25 \pm 0.14, P=0.004)$. After adjusting for age, gender, BMI, UV index, history of diabetes, and hypertension, smoking and dietary carotenoids were significant factors affecting the MPOD. Smokers had a lower MPOD than the non- smokers $(0.16$ $(0.09-0.23)$ vs $0.28(0.22-0.34), P=0.026)$ and first quartile of dietary carotenoid intake had a lower MPOD than the fourth quartile (0.14 (0.08-0.21) vs 0.33 (0.24-0.43), $P=0.012$ ). Figure 2 shows the correlation of MPOD with pack years of smoking. The regression equation for MPOD vs smoking was: $\mathrm{MPOD}=0.23-0.004 \times$ smoking (pack years) and the associated $R^{2}$ was 0.21 . There was a statistically significant inverse relationship between smoking pack years for the smokers and MPOD $(r=-0.458, P=0.048)$.

Figure 3 shows the correlation of MPOD with dietary carotenoid intake. The regression equation for MPOD vs dietary carotenoid was: $\mathrm{MPOD}=-0.005+0.018 \times$

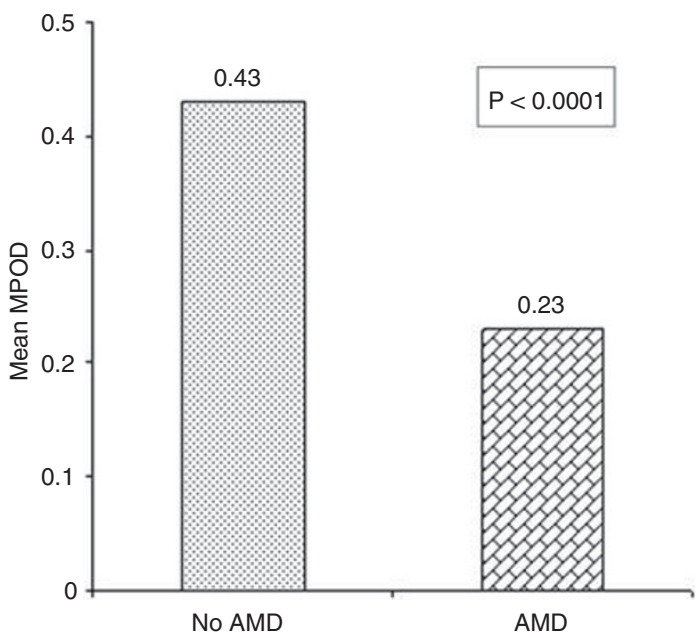

Figure 1 MPOD among subjects with and without AMD. AMD: Age-related macular degeneration, MPOD: Macular pigment optical density. dietary carotenoid $(\mathrm{mg} / \mathrm{d})$ and the associated $R^{2}$ was 0.28 . The positive relationship between MPOD and dietary carotenoids was statistically significant $(r=0.505$, $P<0.0001)$.

In order to minimize bias, inter-observer variability for the measurement of MPOD was compared between two observers, where the Cronbach's $\alpha$ value was 0.983 .

Figure 4 shows the Bland-Altman plot for the differences in measurements by the two observers vs the means of the measurements, showing the mean difference in the MPOD measurements to be -0.0044 , with limits of agreement ranged from 0.0787 to -0.0875 .

\section{Discussion}

This study reports on the mean MPOD in wet AMD in a population of south Indian ethnicity. Though the

Table 1 Mean MPOD among the subgroups

\begin{tabular}{|c|c|c|c|c|}
\hline \multirow{3}{*}{ Variable } & \multicolumn{4}{|c|}{$M P O D$ in $A M D$} \\
\hline & \multicolumn{2}{|c|}{ Unadjusted } & \multicolumn{2}{|l|}{ Adjusted $^{\mathrm{a}}$} \\
\hline & Mean $\pm S D$ & $\mathrm{P}$ & Mean $(95 \%$ CI) & $\mathrm{P}$ \\
\hline \multicolumn{5}{|l|}{ Gender } \\
\hline Male & $0.20 \pm 0.12$ & \multirow{2}{*}{0.101} & $0.23(0.18-0.28)$ & \multirow{2}{*}{0.976} \\
\hline Female & $0.28 \pm 0.14$ & & $0.23(0.15-0.31)$ & \\
\hline \multicolumn{5}{|l|}{ Age group (years) } \\
\hline$\leq 69$ & $0.19 \pm 0.11$ & \multirow{3}{*}{0.610} & $0.19(0.11-0.27)$ & \multirow{3}{*}{0.457} \\
\hline$\overline{70}-74$ & $0.23 \pm 0.14$ & & $0.27(0.18-0.35)$ & \\
\hline$\geq 75$ & $0.25 \pm 0.14$ & & $0.23(0.16-0.31)$ & \\
\hline \multicolumn{5}{|l|}{ BMI group } \\
\hline Lean & $0.22 \pm 0.23$ & \multirow{4}{*}{0.759} & $0.31(0.14-0.48)$ & \multirow{4}{*}{0.298} \\
\hline Normal & $0.27 \pm 0.13$ & & $0.27(0.18-0.35)$ & \\
\hline Overweight & $0.22 \pm 0.16$ & & $0.15(0.02-0.27)$ & \\
\hline Obese & $0.21 \pm 0.11$ & & $0.21(0.16-0.27)$ & \\
\hline \multicolumn{5}{|l|}{ Smoking status } \\
\hline Non-smoker & $0.27 \pm 0.12$ & \multirow{2}{*}{0.041} & $0.28(0.22-0.34)$ & \multirow{2}{*}{0.026} \\
\hline Ex-smoker & $0.18 \pm 0.12$ & & $0.16(0.09-0.23)$ & \\
\hline \multicolumn{5}{|l|}{ UV index } \\
\hline First quartile & $0.29 \pm 0.15$ & \multirow{4}{*}{0.451} & $0.23(0.12-0.34)$ & \multirow{4}{*}{0.938} \\
\hline Second quartile & $0.22 \pm 0.17$ & & $0.26(0.15-0.36)$ & \\
\hline Third quartile & $0.23 \pm 0.08$ & & $0.22(0.14-0.31)$ & \\
\hline Fourth quartile & $0.19 \pm 0.12$ & & $0.22(0.14-0.29)$ & \\
\hline \multicolumn{5}{|l|}{$\mathrm{H} / \mathrm{O}$ diabetes } \\
\hline Absent & $0.21 \pm 0.13$ & \multirow{2}{*}{0.546} & $0.21(0.15-0.27)$ & \multirow{2}{*}{0.384} \\
\hline Present & $0.24 \pm 0.13$ & & $0.25(0.19-0.31)$ & \\
\hline \multicolumn{5}{|l|}{ H/O hypertension } \\
\hline Absent & $0.25 \pm 0.13$ & \multirow{2}{*}{0.384} & $0.25(0.19-0.31)$ & \multirow{2}{*}{0.238} \\
\hline Present & $0.21 \pm 0.12$ & & $0.20(0.15-0.26)$ & \\
\hline \multicolumn{5}{|l|}{ Dietary carotenoids } \\
\hline First quartile & $0.15 \pm 0.07$ & \multirow{4}{*}{0.004} & $0.14(0.08-0.21)$ & \multirow{4}{*}{0.012} \\
\hline Second quartile & $0.26 \pm 0.14$ & & $0.27(0.19-0.35)$ & \\
\hline Third quartile & $0.34 \pm 0.09$ & & $0.33(0.24-0.43)$ & \\
\hline Fourth quartile & $0.25 \pm 0.14$ & & $0.25(0.13-0.36)$ & \\
\hline
\end{tabular}

Abbreviations: MPOD, macular pigment optical density; AMD, age-related macular degeneration; BMI, body mass index; BCVA, best-corrected visual acuity; UV, ultraviolet; $\mathrm{H} / \mathrm{O}$, history of; $\mathrm{CI}$, confidence interval.

a Adjusted for gender, age, BMI, smoking status, BCVA, UV index, H/O diabetes, $\mathrm{H} / \mathrm{O}$ hypertension, and dietary carotenoids.

Bold values are statistically significant. 


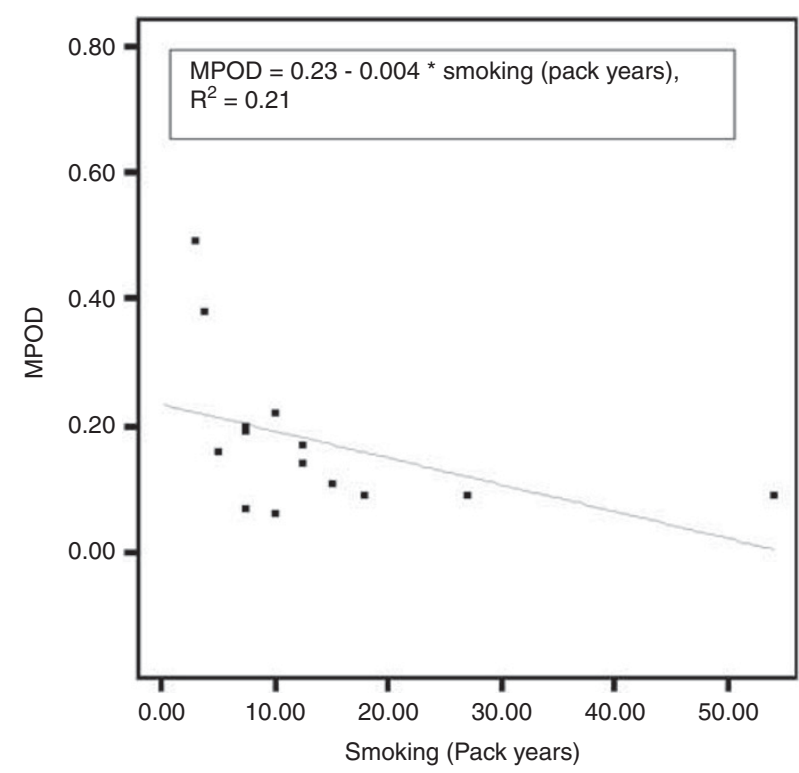

Figure 2 Relationship between MPOD and pack years of smoking. MPOD: Macular pigment optical density.

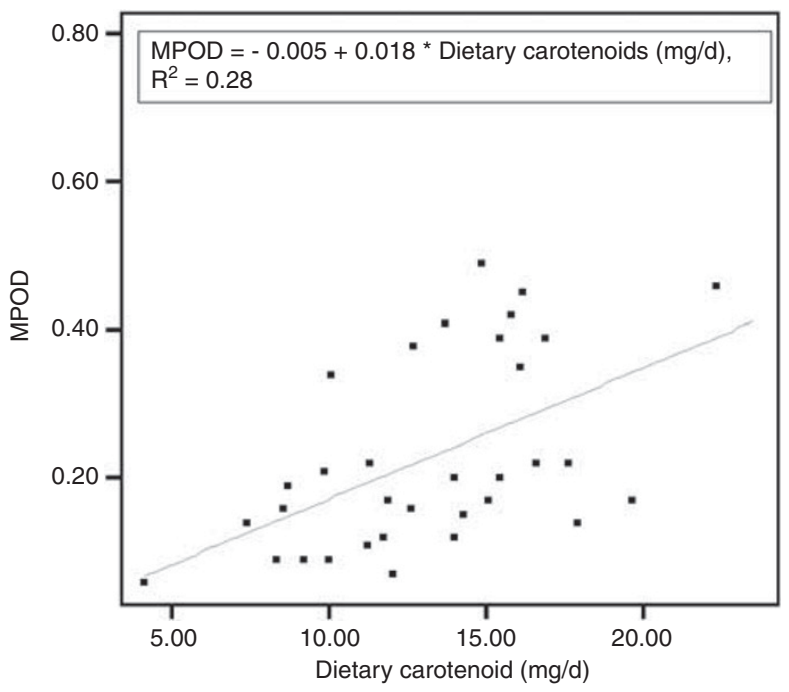

Figure 3 Relationship between MPOD and dietary carotenoids. MPOD: Macular pigment optical density.

normative data of MPOD in this population has been established, ${ }^{17}$ this study is unique, as it is the first report of MPOD in patients with wet AMD in the Indian population.

Age- and gender-adjusted mean MPOD in AMD and those without AMD was 0.23 and $0.43 \log$ units, $P<0.0001$.

There is a growing body of evidence in support of the view that MP protects against AMD. ${ }^{18}$ This evidence includes parallels between a relative lack of MP and risk factors for AMD. ${ }^{19,20}$ The lack of MP in this study may be the consequence (as opposed to the cause) of the wet $\mathrm{AMD}$, because of loss of photoreceptors (in which the

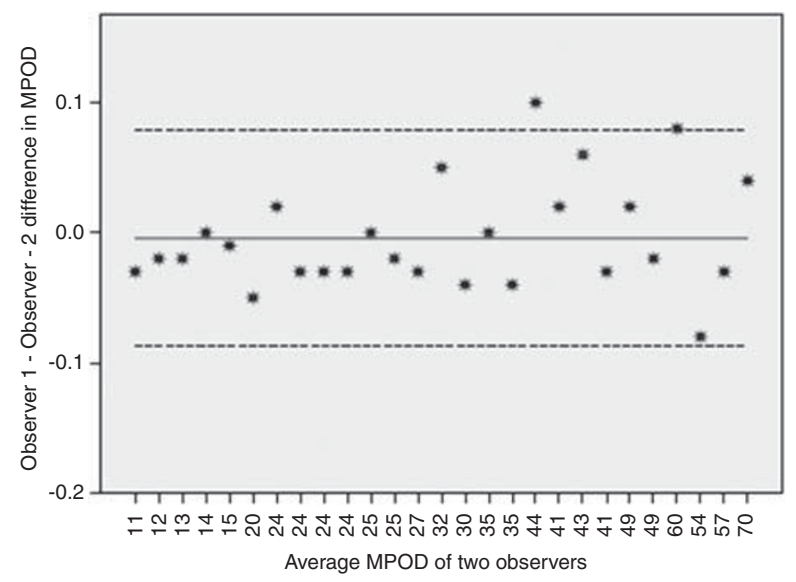

Figure 4 Bland-Altman plot for MPOD showing difference between measurements by two observers versus the average MPOD of the two observers.

MP is housed). ${ }^{21}$ Table 2 shows the percentage decrease of MPOD in AMD across various ethnicities ranging from 0 to $65 \%$ (mean $37.85 \%$ ). ${ }^{22-29}$ Previous results of cross-sectional studies could be biased by the recent use of lutein and zeaxanthin supplements. ${ }^{22,24,26,28}$ The dietary levels of luetin and zeaxanthin between the controls and wet AMD cases were found to be similar. The rationale for this being that retinas with wet AMD may uptake and metabolize lutein and zeaxanthin differently to control eyes even if dietary levels are similar between groups.

Though there are lack of studies associating the MPOD level, AMD, and smoking status, there are some studies on association between cigarette smoking and low MPOD levels ${ }^{30,31}$ and smoking to be a risk factor for AMD. ${ }^{32,33}$ Our findings are identical to those reported by Hammond et al ${ }^{30}$ who reported that current cigarette smokers had a significantly less MPOD (53\%) than the control patients (mean MPOD: 0.16 vs 0.34, respectively, $P<0.01$ ). Consistent with this, we found that smokers had a significantly lower MPOD (30\%) than never smokers. Further, we demonstrated an inverse relationship between smoking frequency and MPOD ( $r=-0.458, P=0.048)$, which is again consistent with the report of Hammond et $a l^{30}(r=-0.498, P<0.01)$. Similarly, Nolan et al ${ }^{31}$ showed an inverse relation between the two $(r=-0.239, P<0.01)$. The possible explanations to account for a relative lack of MP amongst cigarette smokers include a poor diet (with consequentially reduced levels of antioxidants) and/or increased overall oxidant load associated with tobacco use. ${ }^{30,31}$

The biochemical mechanisms that mediate the selective uptake, concentration, transport, and the stabilization of the macular carotenoids are not clear. ${ }^{18}$ There is a good correlation between increase in dietary carotenoids and serum carotenoids, which might assist 
Table 2 Comparison of different studies showing reduction of MP in AMD

\begin{tabular}{|c|c|c|c|c|c|c|c|}
\hline Reference & Ethnicity & Method & $\begin{array}{l}\text { No. of } \\
\text { subjects }\end{array}$ & $\begin{array}{l}\text { Age range } \\
\text { (years) }\end{array}$ & $\begin{array}{l}\text { Mean } M P O D \\
\text { in } A M D\end{array}$ & $\begin{array}{c}\text { Mean } M P O D \\
\text { in no } A M D\end{array}$ & $\begin{array}{c}\% \text { Decrease of } \\
M P O D \text { in } A M D\end{array}$ \\
\hline Berendschot et al ${ }^{22,30}$ & Caucasian & RFS & 435 & $\geq 55$ & $0.33 \pm 0.16$ & $0.33 \pm 0.15$ & 0 \\
\hline Beatty et al 21,23 & Caucasian & HFP & 18 & $21-81$ & $0.147 \pm 0.144$ & $0.311 \pm 0.206$ & 52 \\
\hline Ciulla et $a l^{24}$ & US & HFP & 449 & $18-88$ & $0.26 \pm 0.21$ & $0.28 \pm 0.21$ & 8 \\
\hline Bone et $a l^{25,41}$ & Mixed & HPLC & 112 & $58-98$ & - & - & 62 \\
\hline Obana et $a l^{26}$ & Asian & RS & 287 & $50-85$ & $1471 \mathrm{RC}$ & $523.5 \mathrm{RC}$ & 65 \\
\hline Bernstein et $a l^{27}$ & Mixed & RS & 313 & $21-84$ & $148 \pm 147 \mathrm{RC}$ & $219 \pm 134 \mathrm{RC}$ & 32 \\
\hline Stringham et $\mathrm{l}^{28}$ & NA & HFP & 28 & $55-82$ & $0.37 \pm 0.24$ & - & - \\
\hline Jahn et $a l^{29}$ & Caucasian & $\mathrm{AF}$ & 146 & $50-88$ & $0.239 \pm 0.09 \mathrm{DU}$ & - & - \\
\hline Our study & Asian & HFP & 62 & $55-89$ & 0.23 & 0.43 & 46 \\
\hline
\end{tabular}

Abbreviations: RFS, SpectRal fundus reflectance; HFP, heterochromatic flicker photometry; RS, resonance Raman spectroscopy; AF, auto fluorescence; HPLC, high performance liquid chromatography; RC, Raman count; DU, density units; NA, not available.

in the constant replenishment of the macular pigments. ${ }^{31,34,35}$ Previous studies with FFQ have reported a positive relation between dietary intake of lutein/zeaxanthin and the MPOD, which is similar to our results. ${ }^{31,34-41}$ Previous studies showed that MPOD was $19-31 \%{ }^{31,36,37}$ higher in the highest level of dietary intake of carotenoids, which is comparable to our results showing $48 \%$ higher in the same level.

The strength of the study is that it is the first report of MPOD in patients with wet AMD in the Indian subcontinent. In contrast to other studies, the subjects on dietary supplementation of carotenoids were excluded from this study. Smoking and UV exposure was collected with standardized techniques from the patients. One limitation of this study was the lower sample size.

The age-gender-adjusted MPOD of patients with wet AMD aged $\geq 50$ years was found to be 0.23 and that of the controls was 0.44 in a population of south Indian ethnicity.

\section{Summary}

What was known before

- Epidemiological studies have shown a controversial relationship between age-related macular degeneration (AMD) and the macular pigment optical density (MPOD). Although a few studies have shown an inverse relationship between AMD and MPOD, most failed to prove any relationship.

What this study adds

- This study establishes the MPOD in adult Indian population with wet AMD. We found an inverse association between wet AMD and MPOD in Indian population.

\section{Conflict of interest}

The authors declare no conflict of interest.

\section{References}

1 Krishnan T, Ravindran RD, Murthy GV, Vashist P, Fitzpatrick KE, Thulasiraj RD et al. Prevalence of early and late age-related macular degeneration in India: the INDEYE study. Invest Ophthalmol Vis Sci 2010; 51: 701-707.

2 Krishnaiah S, Das T, Nirmalan PK, Nutheti R, Shamanna $\mathrm{BR}$, Rao GN et al. Risk factors for age-related macular degeneration: findings from the Andhra Pradesh eye disease study in South India. Invest Ophthalmol Vis Sci 2005; 46: 4442-4449.

3 Bressler NM. Early detection and treatment of neovascular age related macular degeneration. J Am Board Fam Pract 2002; 15: 142-152.

4 Rajan SI, Sarma PS, Mishra US. Demography of Indian aging, 2001-2051. J Aging Soc Policy 2003; 15: 11-30.

5 Vingerling JR, Dielemans I, Hofman A, Grobbee DE, Hijmering M, Kramer CF et al. The prevalence of age-related maculopathy in the Rotterdam Study. Ophthalmol 1995; 102: 205-210.

6 Mitchell P, Smith W, Attebo K, Wang JJ. Prevalence of agerelated maculopathy in Australia. The Blue Mountains Eye Study. Ophthalmol 1995; 102: 1450-1460.

7 Moeller SM, Parekh N, Tinker L, Ritenbaugh C, Wallace RB. CAREDS Research Study Group. Associations between intermediate age-related macular degeneration and lutein and zeaxanthin in CAREDS. Arch Ophthalmol 2006; 124: 1151-1162.

8 SanGiovanni JP, Chew EY, Clemons TE, Ferris FL 3rd, Gensler G, Lindblad AS et al. AREDS Research group. The relationship of dietary carotenoids and Vitamin A, E and C intake with age-related macular degeneration in a casecontrol study. AREDS Report no. 22. Arch Ophthal 2007; 125: 1225-1232.

9 Bird AC, Bressler NM, Bressler SB, Chisholm IH, Coscas G, Davis MD et al. An international classification and grading system for age-related maculopathy and age-related macular degeneration. The International ARM Epidemiological Study Group. Surv Ophthalmol 1995; 39: 367-374.

10 Leffondré K, Abrahamowicz M, Siemiatycki J, Rachet B. Modeling smoking history: a comparison of different approaches. Am J Epidemiol 2002; 156: 813-823.

11 Hebert JR, Gupta PC, Bhonsle RB, Murti PR, Mehta H, Verghese $\mathrm{F}$ et al. Development and testing of a quantitative 
food frequency questionnaire for use in Kerala, India. Public Health Nutr 1998; 1: 123-130.

12 McCarty CA, Lee SE, Livingston PM, Bissinella M, Taylor HR. Ocular exposure to UV-B in sunlight: the Melbourne visual impairment project model. Bull World Health Organ 1996; 74: 353-360.

13 Narendran V, John RK, Raghuram A, Ravindran RD, Nirmalan PK, Thulasiraj RD. Diabetic retinopathy among self-reported diabetics in southern India: a populationbased assessment. Br J Ophthalmol 2002; 86: 1014-1018.

14 Kohner EM, Aldington SJ, Stratton IM, Manley SE, Holman RR, Matthews DR et al. United Kingdom prospective diabetes study: diabetic retinopathy at diagnosis of noninsulin dependent diabetes mellitus and associated risk factors. Arch Ophthalmol 1998; 116: 297-303.

15 Snodderly DM, Mares JA, Wooten BR, Oxton L, Gruber M. CAREDS Macular Pigment Study Group. Macular pigment measurement by heterochromatic flicker photometry in older subjects: The Carotenoids and Age-Related Eye Disease Study. Invest Ophthalmol Vis Sci 2004; 45: 531-538.

16 Wooten BR, Hammond BR Jr, Land RI, Snodderly DM. A practical method for measuring macular pigment optical density. Invest Ophthalmol Vis Sci 1999; 40: 2481-2489.

17 Raman R, Rajan R, Biswas S, Vaitheeswaran K, Sharma T. Macular pigment optical density in a South Indian population. Invest Ophthalmol Vis Sci 2011; 52: 7910-7916.

18 Loane E, Nolan JM, O'Donovan O, Bhosale P, Bernstein PS, Beatty S. Transport and retinal capture of lutein and zeaxanthin with reference to age-related macular degeneration. Surv Ophthalmol 2008; 53: 68-81.

19 Snodderly DM. Evidence for protection against age-related macular degeneration by carotenoids and antioxidant vitamins. Am J Clin Nutr 1995; 62: 1448S-1461S.

20 Mozaffarieh M, Sacu S, Wedrich A. The role of the carotenoids, lutein and zeaxanthin, in protecting against age-related macular degeneration: a review based on controversial evidence. Nutr J 2003; 2: 1-8.

21 Beatty S, Boulton M, Henson D, Koh HH, Murray IJ. Macular pigment and age related macular degeneration. Br J Ophthalmol 1999; 83(7): 867-877.

22 Berendschot TT, Willemse-Assink JJ, Bastiaanse M, de Jong PT, van Norren D. Macular pigment and melanin in agerelated maculopathy in a general population. Invest Ophthalmol Vis Sci 2002; 43: 1928-1932.

23 Beatty S, Murray IJ, Henson DB, Carden D, Koh H, Boulton ME. Macular pigment and risk for age-related macular degeneration in subjects from a Northern European population. Invest Ophthalmol Vis Sci 2001; 42: 439-446.

24 Ciulla TA, Hammond BR Jr. Macular pigment density and aging, assessed in the normal elderly and those with cataracts and age-related macular degeneration. $A m \mathrm{~J}$ Ophthalmol 2004; 138: 582-587.

25 Bone RA, Landrum JT, Mayne ST, Gomez CM, Tibor SE, Twaroska EE. Macular pigment in donor eyes with and without AMD: a case-control study. Invest Ophthalmol Vis Sci 2001; 42: 235-240.

26 Obana A, Hiramitsu T, Gohto Y, Ohira A, Mizuno S, Hirano $\mathrm{T}$ et al. Macular carotenoid levels of normal subjects and age-related maculopathy patients in a Japanese population. Ophthalmology 2008; 115: 147-157.

27 Bernstein PS, Zhao DY, Wintch SW, Ermakov IV, McClane RW, Gellermann W. Resonance Raman measurement of macular carotenoids in normal subjects and in age-related macular degeneration patients. Ophthalmology. 2002 109: 1780-1787.

28 Stringham JM, Hammond BR, Nolan JM, Wooten BR, Mammen A, Smollon W et al. The utility of using customized heterochromatic flicker photometry (cHFP) to measure macular pigment in patients with age-related macular degeneration. Exp Eye Res 2008; 87: 445-453.

29 Jahn C, Wüstemeyer H, Brinkmann C, Trautmann S, Mössner A, Wolf S. Macular pigment density in age-related maculopathy. Graefes Arch Clin Exp Ophthalmol 2005; 243(3): 222-227.

30 Hammond BR Jr, Wooten BR, Snodderly DM. Cigarette smoking and retinal carotenoids: implications for agerelated macular degeneration. Vis Res 1996; 36: 3003-3009.

31 Nolan JM, Stack J, O'Connell E, Beatty S. The relationships between macular pigment optical density and its constituent carotenoids in diet and serum. Invest Ophthal Vis Sci 2007; 48: 571-582.

32 Schmidt S, Hauser MA, Scott WK, Postel EA, Agarwal A, Gallins $\mathrm{P}$ et al. Cigarette smoking strongly modifies the association of LOC387715 and age-related macular degeneration. Am J Hum Genet 2006; 78: 852-864.

33 DeAngelis MM, Ji F, Kim IK, Adams S, Capone A Jr, Ott J et al. Cigarette smoking, CFH, APOE, ELOVL4, and risk of neovascular age-related macular degeneration. Arch Ophthalmol 2007; 125: 49-54.

34 Nolan JM, Stack J, Donovan O, Loane E, Beatty S. Risk factors for age-related maculopathy are associated with a relative lack of macular pigment. Exp Eye Res 2007; 84: 61-74.

35 Curran-Celentano J, Hammond BR Jr, Ciulla TA, Cooper DA, Pratt LM, Danis RB. Relation between dietary intake, serum concentrations, and retinal concentrations of lutein and zeaxanthin in adults in a Midwest population. Am J Clin Nutr 2001; 74: 796-802.

36 Mares JA, LaRowe TL, Snodderly DM, Moeller SM, Gruber MJ, Klein ML et al. CAREDS Macular Pigment Study Group and Investigators. Predictors of optical density of lutein and zeaxanthin in retinas of older women in the Carotenoids in Age-Related Eye Disease Study, an ancillary study of the Women's Health Initiative. Am J Clin Nutr 2006; 84: 1107-1122.

37 Hammond BR Jr, Johnson EJ, Russell RM, Krinsky NI, Yeum KJ, Edwards RB. Dietary modification of human macular pigment density. Invest Ophthal Vis Sci 1997; 38: 1795-1801.

38 Burke JD, Curran-Celentano J, Wenzel AJ. Diet and serum carotenoid concentrations affect macular pigment optical density in 45 years and older. J Nutr 2005; 135: 1208-1214.

39 Wenzel AJ, Sheehan JP, Gerweck C, Stringham JM, Fuld K, Curran-Celentano J. Macular pigment optical density during 120 days of lutein supplementation. Ophthalmic Physiol Opt 2007; 27: 329-335.

40 Berendschot TT, Goldbohm RA, Klöpping WA, van de Kraats J, van Norel J, van Norren D. Influence of lutein supplementation on macular pigment, assessed with two objective techniques. Invest Ophthalmol Vis Sci 2000; 41: 3322-3326.

41 Bone RA, Landrum JT, Guerra LH, Ruiz CA. Lutein and zeaxanthin dietary supplements raise macular pigment optical density and serum concentrations of these carotenoids in humans. J Nutr 2003; 133: 992-998. 